\title{
Contribution of nonadiabatic ions to the cross-tail current in an $\mathrm{O}^{+}$dominated thin current sheet
}

\author{
L. M. Kistler, ${ }^{1}$ C. Mouikis, ${ }^{1}$ E. Möbius, ${ }^{1}$ B. Klecker, ${ }^{2}$ J. A. Sauvaud ${ }^{3}$ H. Réme ${ }^{3}$ \\ A. Korth, ${ }^{4}$ M. F. Marcucci, ${ }^{5}$ R. Lundin, ${ }^{6}$ G. K. Parks, ${ }^{7}$ and A. Balogh ${ }^{8}$ \\ Received 25 June 2004; revised 23 March 2005; accepted 8 April 2005; published 24 June 2005.
}

[1] During storm times, $\mathrm{O}^{+}$can dominate both the pressure and the density in the plasma sheet. Because of the contribution from ion outflow, the plasma sheet is already oxygen-rich prior to substorm onset. At substorm onset the fraction of $\mathrm{O}^{+}$ contributing to the pressure and density increases. In the $\mathrm{O}^{+}$dominated thin current sheet the $\mathrm{O}^{+}$ions are observed to stream from dawn to dusk across the tail, as predicted for nonadiabatic ions by Speiser (1965). We calculate the current contribution from these ions and find that they carry about $5-10 \%$ of the cross-tail current. During a nonstormtime substorm the general behavior of the $\mathrm{O}^{+}$is the same. However, because there is less $\mathrm{O}^{+}$present, the $\mathrm{O}^{+}$never dominates over $\mathrm{H}^{+}$, and the contribution to the cross-tail current is even less.

Citation: Kistler, L. M., et al. (2005), Contribution of nonadiabatic ions to the cross-tail current in an $\mathrm{O}^{+}$dominated thin current sheet, J. Geophys. Res., 110, A06213, doi:10.1029/2004JA010653.

\section{Introduction}

[2] When a current sheet becomes thin compared to the Larmor radius of the ions, the ion motion becomes nonadiabatic. The motion of nonadiabatic particles in a thin current sheet was first discussed by Speiser [1965]. He showed that ions with a gyroradius significantly larger than the current sheet thickness would stream along the current sheet from dawn to dusk, gaining energy, until they are ejected and then stream along the magnetic field. It has been shown [Eastwood, 1972, 1974] that there exist equilibrium models in which these ions are the current carriers in the thin current sheet. Larson and Kaufmann [1996] also showed that a combination of nonadiabatic ion orbit types could generate the observed plasma sheet magnetic field. Kropotkin et al. [1997] developed a self-consistent model of an anisotropic current sheet, where the magnetic tension is balanced by the finite inertia of the ions, again showing that ions could be the dominant current carriers. Sitnov et al. [2000] developed a more generalized approach that was not limited by the strong anisotropy case. Under the assumption that ions were the main current carriers, they were able to find

\footnotetext{
${ }^{1}$ Space Science Center, University of New Hampshire, Durham, New Hampshire, USA.

${ }^{2}$ Max-Planck-Institute für Extraterrestriche Physik, Garching, Germany.

${ }^{3}$ Centre d'Etude Spatiale des Rayonnements, Toulouse, France.

${ }^{4}$ Max-Planck-Institute für Aeronomie, Lindau, Germany.

${ }^{5}$ Istituto di Fisica dello Spazio Interplanetario, Rome, Italy.

${ }^{6}$ Swedish Institute for Space, Kiruna, Sweden.

${ }^{7}$ Space Sciences Laboratory, University of California, Berkeley, California, USA.

${ }^{8}$ Space and Atmospheric Physics, Imperial College, London, UK.
}

Copyright 2005 by the American Geophysical Union. 0148-0227/05/2004JA010653 a self-consistent equilibrium for arbitrary ion anisotropy. Sitnov et al. [2003] extended their model to a bifurcated current sheet structure, and showed that depending on the ion anisotropy outside the current sheet, either electrons or ions could dominate the current. On the other hand, other kinetic and MHD simulations [e.g., Hesse and Winske, 1994; Pritchett and Coroniti, 1995; Hesse et al., 1996; Schindler and Birn, 2002] have found that the current is predominantly carried by electrons. Whether configurations with the current carried by nonadiabatic ions exist, or are common in the plasma sheet, has not been shown. Mitchell et al. [1990] analyzed the current in the near-Earth $(10 \mathrm{Re})$ region during a substorm. They found that there was a short time at the end of the growth phase where the ion anisotropies showed predominantly dawn-to-dusk motion. In this case, they calculated that the current from these ions would be enough to carry the full current sheet current. Asano et al. [2003] measured the cross-tail current during a substorm at $-15 \mathrm{Re}$, and found that the electrons were the primary current carriers in the late growth phase and early expansion phase.

[3] The Cluster satellites, with their apogee at $19 \mathrm{Re}$, are in an ideal location to observe thin current sheets in the vicinity of the near-Earth neutral line during a substorm. It is the intent of this paper to examine a few example cases in order to determine the contribution of the nonadiabatic ions to the cross-tail current. During a storm, the interesting situation arises where there is a thin current sheet and the plasma is dominated by oxygen. Because $\mathrm{O}^{+}$has a larger Larmor radius than protons at the same energy, these are the most likely cases to find the plasma sheet dynamics dominated by the nonadiabatic ions. Under these circumstances, these ions may also carry a large fraction of the current. Thus we have selected two storm-time and one non-stormtime substorms in which to study the ion distribution 
functions. We look for evidence of nonadiabatic ions, streaming dawn to dusk, and calculate the contribution of these ions to the current.

\section{Instrumentation}

[4] The Cluster satellites are in polar orbits with an apogee of $19 \mathrm{Re}$ and a perigee of $4 \mathrm{Re}$. The data shown here are mainly from the CODIF sensor of the CIS instrument [Reme et al., 2001]. CODIF measures the threedimensional distribution functions of the major ion species over the energy per charge range $40-40,000 \mathrm{eV} / \mathrm{e}$. It is a combination of a top hat electrostatic analyzer followed by postacceleration of $15 \mathrm{kV}$, and then a time-of-flight measurement. It can resolve the major ion species, $\mathrm{H}^{+}, \mathrm{He}^{++}$, $\mathrm{He}^{+}$and $\mathrm{O}^{+}$. For this paper we will concentrate on observations of $\mathrm{H}^{+}$and $\mathrm{O}^{+}$in the plasma sheet. Unless otherwise noted, the moments of the distribution are calculated over the full range of $40-40,000 \mathrm{eV} / \mathrm{e}$.

\section{Observations}

\subsection{Observations on 1 October 2001}

[5] On 1 October 2001, a geomagnetic storm with a minimum Dst of $-150 \mathrm{nT}$ occurred. The minimum Dst occurred at 8:00 UT. Coverage of the Cluster satellites also began at 8:00 UT, and continued until the end of the day. Multiple substorms occurred during the main phase and recovery phase of this storm. We will concentrate on the largest, which occurred at about 9:30. Figure 1 shows Spacecraft 4 data for the time period from 8:30 to 10:30 UT. Figure 1a shows the total pressure (plasma plus magnetic field). The increased pressure during the growth phase is clearly observed, followed by a decrease at substorm onset. The pressure decreases by almost an order of magnitude, indicating significant unloading during this substorm. Figures $1 \mathrm{~b}$ and $1 \mathrm{c}$ show $\mathrm{H}^{+}$and $\mathrm{O}^{+}$energy spectrograms. After substorm onset, both the $\mathrm{H}^{+}$and $\mathrm{O}^{+}$spectra change dramatically. The $\mathrm{O}^{+}$spectrum becomes dominated by a much higher energy population. Figure 1d shows the $\mathrm{H}^{+}$velocity in the $\mathrm{X}$ direction, $\mathrm{V}_{\mathrm{x}}$. First tailward flows are observed, indicating that the reconnection line is earthward of the spacecraft, followed by earthward flows. This is consistent with the findings of Runov et al. [2003] that the spacecraft is very close to the reconnection point in this event. Figure 1e shows the current sheet thickness during this time. The thickness is derived by fitting the magnetic field data from spacecraft pairs to a Harris Current Sheet, using the total pressure to determine the lobe pressure boundary condition. From 9:40 to 9:50 UT, the current sheet half-thickness is $1000 \mathrm{~km}$. Thus this is a good example of a storm-time thin current sheet.

[6] Figure 1f shows the $\mathrm{H}^{+}$(black) and $\mathrm{O}^{+}$(blue), contributions to the pressure, while Figure $1 \mathrm{~g}$ shows the ratio of the $\mathrm{O}^{+}$to the $\mathrm{H}^{+}$pressure. Even prior to substorm onset, the $\mathrm{O}^{+} / \mathrm{H}^{+}$pressure ratio was fairly high, at 0.4 . After substorm onset, from about 9:45 to 9:55 UT, the $\mathrm{H}^{+}$pressure has dropped to less than $0.1 \mathrm{nPa}$. During this time, the $\mathrm{O}^{+}$ contribution is still significant, and is dominated by an energetic $(>10 \mathrm{keV})$ component. Because the CODIF instrument has a $40 \mathrm{keV}$ upper limit, the contribution to the pressure from $\mathrm{O}^{+}$is, if anything, an underestimate, as there may be a significant contribution from ions with energies greater than $40 \mathrm{keV}$. The contribution to the density, however, falls off steeply with energy, and is not significantly effected by the upper limit. The $\mathrm{O}^{+} / \mathrm{H}^{+}$pressure ratio is at least 10 . The large $\mathrm{O}^{+} / \mathrm{H}^{+}$pressure ratio is due not so much to an increase in the $\mathrm{O}^{+}$pressure, which is about the same as prior to substorm onset, but to a decrease in the $\mathrm{H}^{+}$pressure. Figures $1 \mathrm{~h}$ and $1 \mathrm{i}$ give the $\mathrm{H}^{+}$(black) and $\mathrm{O}^{+}$ (blue) density, and the density ratio. For density as well, $\mathrm{O}^{+}$ becomes the dominant species. This is the time when the current sheet is thin. Thus we have a thin current sheet dominated by energetic heavy ions. This is exactly the situation when nonadiabatic ion motion would be expected to be important.

[7] This particular event has also been the subject of studies by Runov et al. [2003] and Wygant et al. [2005]. Runov et al. [2003] discuss the bifurcated shape of the current sheet from 09:47 to 09:51 UT. Wygant et al. [2005] discussed electric field structures observed during the crossing at 09:47 UT. In this paper, we are looking for evidence of nonadiabatic ion motion during the crossings to find the contribution of these ions to the current.

[8] As discussed in the introduction, the signature of the nonadiabatic ions expected in a thin current sheet would be ions streaming in the dawn to dusk direction. Figure 2 shows an example of the angular distributions of ions observed from 9:42:10 to $9: 42: 18$ UT in two ways. Figure $2 \mathrm{a}$ shows the full angular distribution for three energy channels centered on $31 \mathrm{keV}, 19 \mathrm{keV}$ and $12 \mathrm{keV}$. The plus and asterisk give the directions parallel and antiparallel to the magnetic field. The white line shows the direction of 90 degree pitch angle. In this case, the tailward direction corresponds with the plus, and the earthward with the asterisk. The $\mathrm{O}^{+}$distributions show the ions at 90 degree pitch angle, in the duskward direction. Figure $2 b$ shows cuts of the distribution in the three GSE planes. The third cut, in the $y-z$ plane, again clearly shows the duskward streaming. This type of anisotropy is exactly what would be expected if there were a source of ions with gyrocenters close to the neutral sheet. This is illustrated in the sketch in Figure 2c. As the ions move out of the neutral sheet and into the magnetic field, they begin gyrating around the field. Because the gyroradius of the ion (about $2000 \mathrm{~km}$ for a $20 \mathrm{keV} \mathrm{O}^{+}$in a $40 \mathrm{nT}$ field) is larger than the half-thickness of the current sheet (about $1000 \mathrm{~km}$ ), the ion returns to the neutral sheet. When the ion moves out into the strong field again, it again returns to the plasma sheet. It thus executes a serpentine motion duskward across the tail. Because the plasma sheet is so thin in this case, and the $\mathrm{O}^{+}$ is so energetic, this is the dominant motion for these ions. We note that a similar anisotropy can be observed at the edge of the plasma sheet because of the density gradient, even for a thick plasma sheet. In that case, it would not indicate that the ions are streaming duskward. Thus the anisotropy alone cannot be used as an indication of the duskward ion streaming. However, the spatial extent over which the anisotropy is observed, combined with the knowledge of the plasma sheet thickness and gyroradius can be used to infer the duskward ion motion.

[9] To determine the spatial and temporal extent of the duskward streaming ions, Figure 3 shows data from 9:38 to 9:50 UT, the thin current sheet time period. Figures $3 \mathrm{a}$ and 


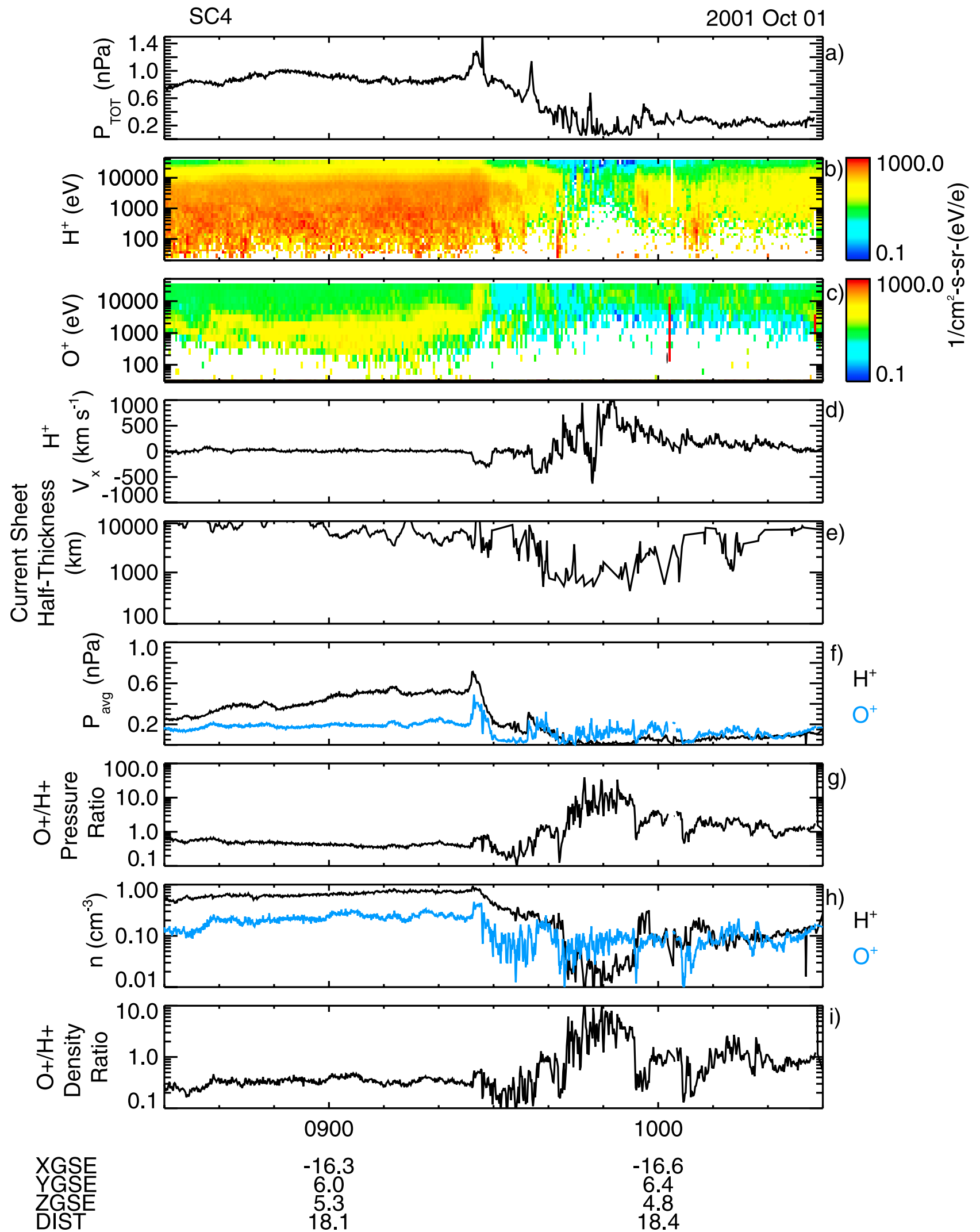

Figure 1. Data from Cluster S/C 4 on 1 October 2001 from 8:30 to 10:30. (a) Total pressure (plasma plus magnetic field), (b) $\mathrm{H}^{+}$differential flux versus energy and time, (c) $\mathrm{O}^{+}$differential flux versus energy and time, (d) $\mathrm{H}^{+}$velocity in $\mathrm{X}_{\mathrm{gse}}$, (e) current sheet thickness, (f) $\mathrm{H}^{+}$(black) and $\mathrm{O}^{+}$(blue) pressure, (g) $\mathrm{O}^{+} / \mathrm{H}^{+}$pressure ratio, (h) $\mathrm{H}^{+}$(black) and $\mathrm{O}^{+}$(blue) density, and (i) $\mathrm{O}^{+} / \mathrm{H}^{+}$density ratio. 
a)

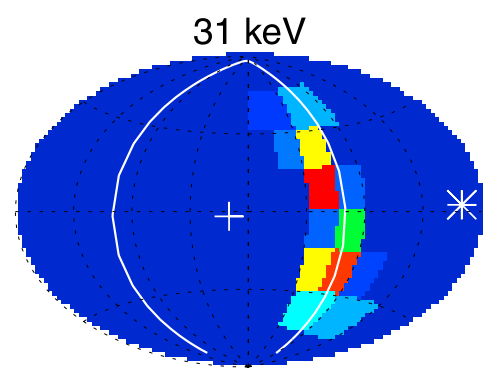

\section{1-10-01/09:42:10 - 09:42:18}
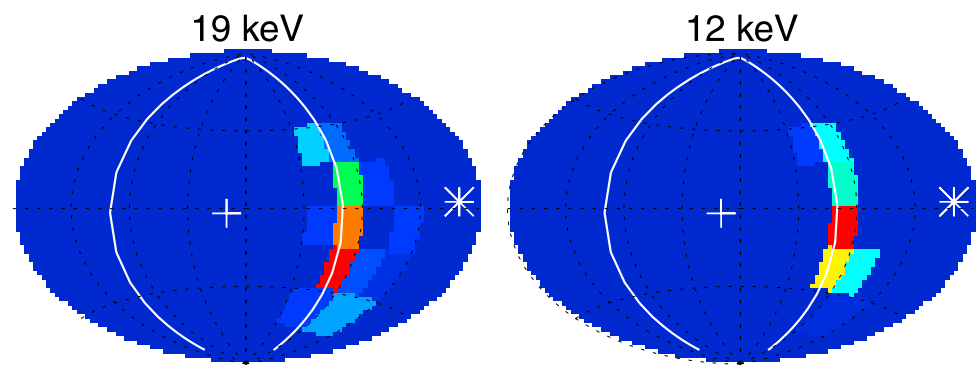

b)
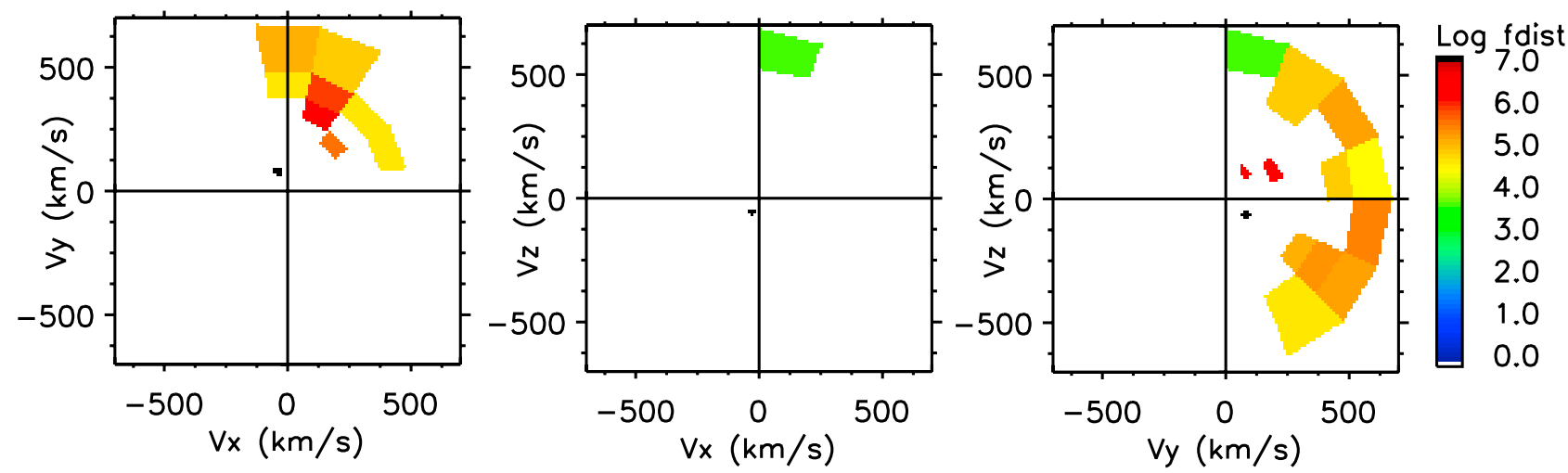

c)

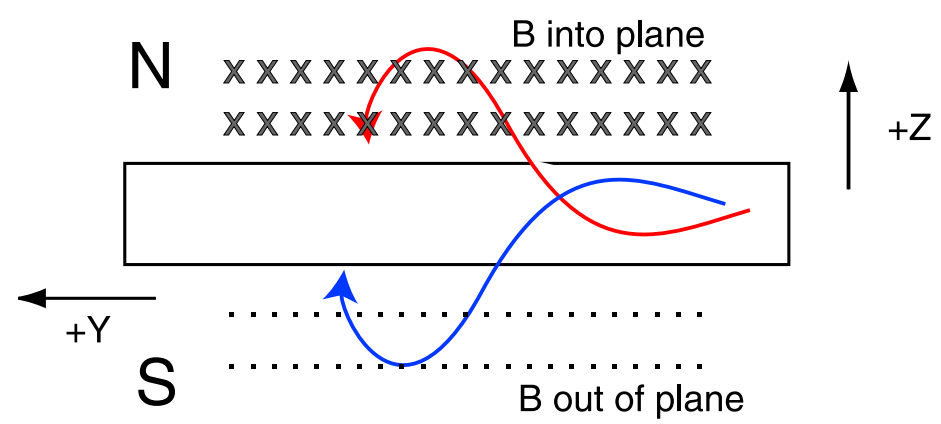

Figure 2. (a) Three-dimensional angular distributions of $\mathrm{O}^{+}$ions from 9:42:10 to 9:42:18 for the top three energy channels, centered at 31,19 , and $12 \mathrm{keV}$. The plus and asterisk give the directions parallel and antiparallel to the magnetic field. The white line shows the direction of $90^{\circ}$ pitch angle. The tailward direction, which is fixed in this display, corresponds in this case to the plus, and the earthward direction corresponds to the asterisk. (b) Cuts of the distribution functions in the GSE coordinate planes for the same time period. (c) Sketch of expected motion of large gyroradius ions in a thin current sheet.

$3 \mathrm{~b}$ show the angular distribution in the spacecraft spin plane for the top $\mathrm{O}^{+}$and $\mathrm{H}^{+}$energy channels $(\sim 25-$ $40 \mathrm{keV}$ ). This plot is equivalent to plotting the equatorial band $\left( \pm 45^{\circ}\right)$ of the 3-D angular distributions like those shown in Figure $2 \mathrm{a}$, as a function of time. The duskward flow can be seen as a line at about $250^{\circ}$. S/C 4 observes this distribution for extended times, from 9:41 to 9:44:10 UT. The energetic $\mathrm{O}^{+}$shows the duskward motion, while the $\mathrm{H}^{+}$, with its smaller gyroradius, does not. We note that while this display gives an indication of where the ions streaming parallel to the current sheet are observed, the full distributions must still be examined to confirm the observation. This is particularly tricky during this time period because, as shown by Wygant et al.
[2005], there is a wave passing through the plasma sheet at this time which changes the normal of the current sheet periodically by almost $90^{\circ}$. We have determined the normal to the current sheet for each of the crossings using minimum variance analysis. For the first crossing, at 9:41:35 UT, the normal components, in GSE, are $\mathrm{N}_{\mathrm{x}}=$ $0.069, \mathrm{~N}_{\mathrm{y}}=0.996$, and $\mathrm{N}_{\mathrm{z}}=0.057$ (i.e., the normal is essentially along the GSE $Y$ axis) while the normal components for the second crossing at 9:42:39 UT are $\mathrm{N}_{\mathrm{x}}=0.159, \mathrm{~N}_{\mathrm{y}}=0.006$, and $\mathrm{N}_{\mathrm{z}}=0.987$ (i.e., the normal is close to the GSE $Z$ axis). The later crossings during this time period show similar shifts. Thus the direction parallel to the current sheet is not always the y direction that we would expect, but can have a substantial com- 

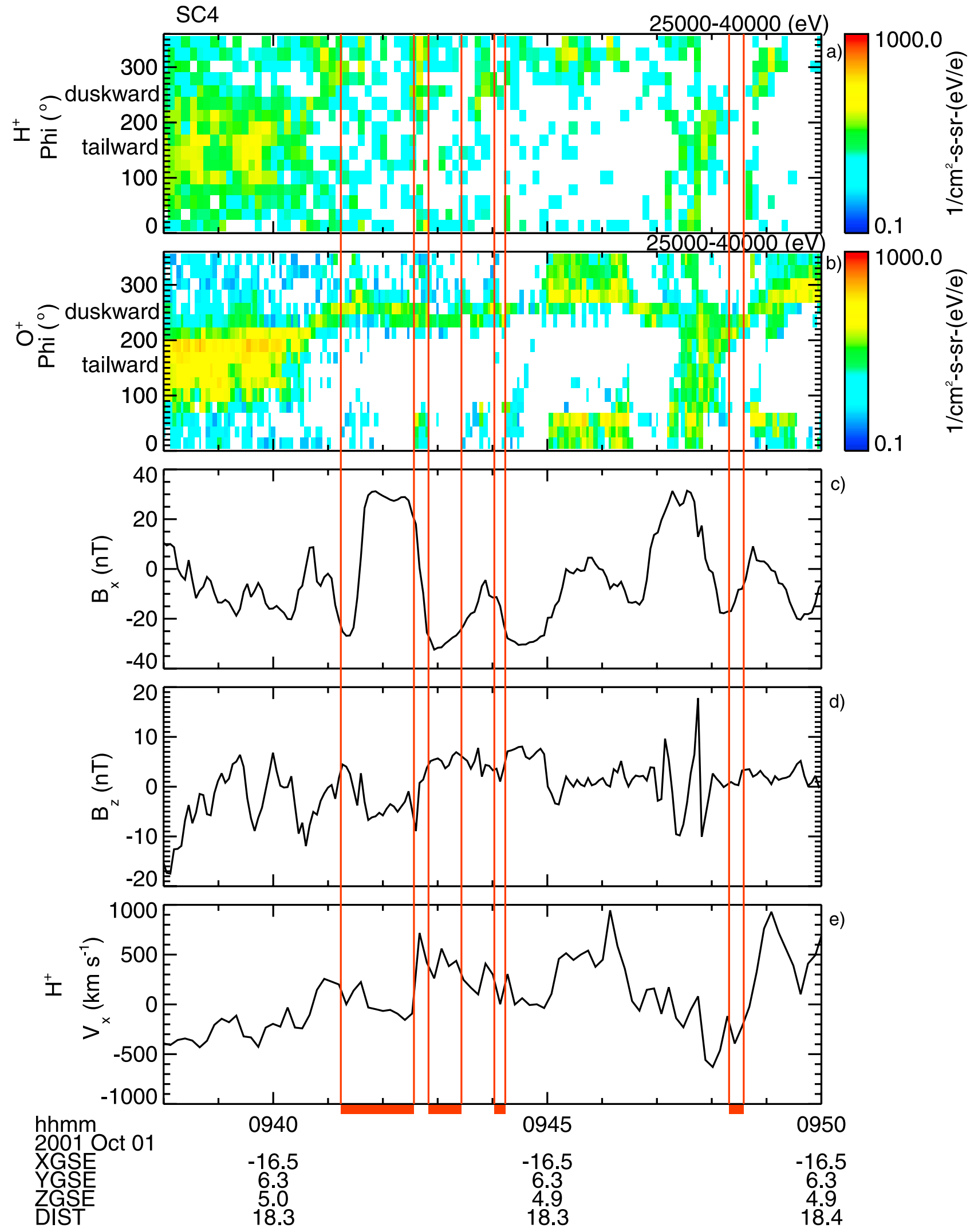

Figure 3. (a) $\mathrm{S} / \mathrm{C} 4 \mathrm{H}^{+}$angular distribution in approximately the $\mathrm{x}-\mathrm{y}$ GSE plane, for $25-40 \mathrm{keV}$ ions. The duskward direction corresponds to 250 degrees. (b) $\mathrm{O}^{+}$angular distribution approximately the $\mathrm{x}-\mathrm{y}$ GSE plane, for $25-40 \mathrm{keV}$ ions. (c) $\mathrm{B}_{\mathrm{x}}$ in GSE coordinates. (d) $\mathrm{B}_{\mathrm{z}}$ in GSE coordinates. (e) $\mathrm{H}^{+} \mathrm{V}_{\mathrm{x}}$ in GSE coordinates. Time periods with Speiser orbits are indicated with red bars. 


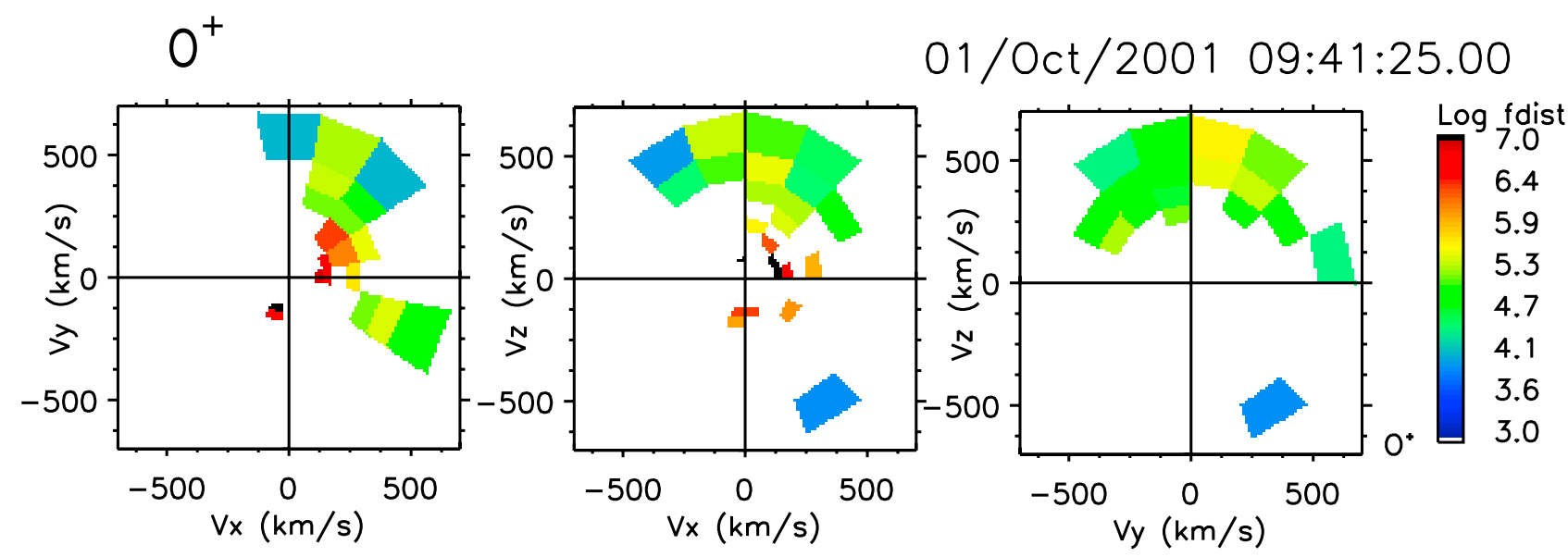

Figure 4. Cuts of the $\mathrm{O}^{+}$distribution for the time period 9:41:25-9:41:29, when the current sheet normal was in the y direction.

ponent in the $\mathrm{z}$ direction. Figure 4 shows an example of the distribution at 9:41:25 UT, when the normal is along y. In this case, the flow of the energetic $\mathrm{O}^{+}$is along $\mathrm{z}$, parallel to the current sheet and perpendicular to the normal. The example in Figure 2 was when the normal was along z. The period around 9:47 UT, when the $\mathrm{O}^{+}$ again shows the duskward motion in this representation, is the period identified by Wygant et al. [2005] in which the full distribution is in fact bidirectional with peaks along the current sheet normal. We have gone through the distributions throughout this time period, and have indicated with red bars along the time axis in Figure 3 the times when the distributions show ions flowing duskward and parallel to the current sheet. Figures $3 \mathrm{c}-$ 3e show the magnetic field $\mathrm{B}_{\mathrm{x}}$ component, magnetic field $\mathrm{B}_{\mathrm{z}}$ component, and the $\mathrm{H}^{+}$velocity, $\mathrm{Vx}$. The increases and decreases in $\mathrm{B}_{\mathrm{x}}$ indicate that the $\mathrm{S} / \mathrm{C}$ location relative to the current sheet location is oscillating, crossing the current sheet multiple times. In addition, the $\mathrm{H}^{+} \mathrm{V}_{\mathrm{x}}$ component turns briefly negative from $9: 41: 45$ to $9: 42: 30$ UT, and at the same time, $B_{\mathrm{z}}$ turns southward, indicating that the spacecraft is located for a short time tailward of the reconnection line. The $\mathrm{O}^{+}$distribution maintains its predominantly duskward anisotropy despite these substantial changes in the magnetic field. This emphasizes that the energetic $\mathrm{O}^{+}$during this time is essentially demagnetized.

[10] Finally, we calculate the contribution of $\mathrm{O}^{+}$to the cross-tail current during the thin current sheet time period. A rough estimate of the total cross-tail current can be calculated from

$$
\mu_{o} I=\int B \cdot d l
$$

For an integration contour in the $\mathrm{x}-\mathrm{z}$ plane with a length $\mathrm{L}$ along $\mathrm{x}$, we get

$$
\mu_{o} I=2 L B_{x}
$$

where $B_{x}$ is the field outside the current sheet. From the total pressure at any time, we can determine the value of the lobe magnetic field, $\mathrm{B}_{\mathrm{x}}$. From this we can determine the necessary total current per unit length needed to support the field:

$$
\frac{I}{L}=\frac{2 \times B_{x}}{\mu_{o}}
$$

For a highly anisotropic flowing plasma, like the duskward streaming $\mathrm{O}^{+}$, the current can be estimated from $\mathrm{j}=$ nev. We can use this to calculate the contribution of the duskward streaming $\mathrm{O}^{+}$. Figure 5 summarizes the current calculation. Figure 5a repeats the phi distribution so that the time periods with duskward streaming can be readily identified. The time periods between the red lines, with the red bars at the bottom are the time periods where the duskward ion motion is observed. Figures $5 \mathrm{~b}$ and $5 \mathrm{c}$ give the $\mathrm{O}^{+}$density and velocity, calculated over the full instrument energy range. Because the velocity along the current sheet is sometimes in " $y$ " and sometimes in " $z$ ", because of the wave, we compute the magnitude of the velocity in the $y-z$ plane for the calculation. Figure $5 \mathrm{~d}$ gives the current calculated from $\mathrm{j}=\mathrm{nev}$, assuming that the distribution is constant over the $2000 \mathrm{~km}$ current sheet thickness. This is supported by our observations of a consistent distribution while $B_{x}$ changes from $-30 \mathrm{nT}$ to $+30 \mathrm{nT}$. Figure $5 \mathrm{e}$ gives the total required cross-tail current, calculated from equation (3), and Figure $5 \mathrm{f}$ shows the fraction of that current carried by the $\mathrm{O}^{+}$. Note that the current is calculated in the spacecraft frame. The contribution of the $\mathrm{O}^{+}$to the total current is about $10 \%$.

[11] Runov et al. [2003] used the curlometer technique to determine the current sheet structure during the later part of this event, from 9:47 to 9:51 UT. The final time period shown in Figure 5, around 9:48:30 UT, corresponds to "crossing B" in that paper. They found that the total current density in the central current sheet during this time was $12 \mathrm{nA} / \mathrm{m}^{2}$. The $\mathrm{O}^{+}$we measured during this time corresponds to $1 \mathrm{nA} / \mathrm{m}^{2}$ (the value shown in Figure 5d, divided by $2000 \mathrm{~km}$ ). This also supports our estimate that the $\mathrm{O}^{+}$ions contribute about $10 \%$ of the total current. 

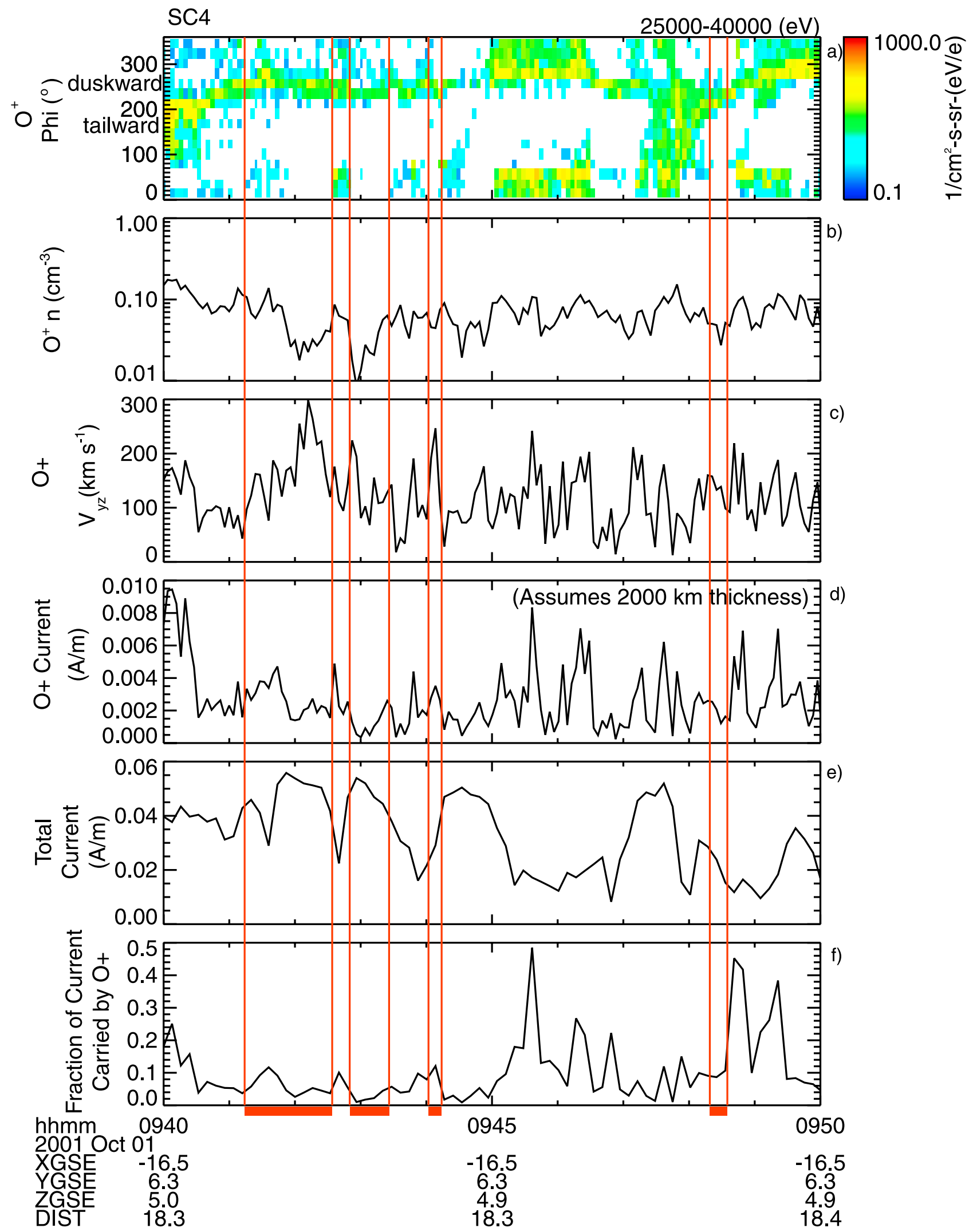

Figure 5. (a) $\mathrm{S} / \mathrm{C} 4$ angular distribution of $25-40 \mathrm{keV} \mathrm{O}^{+}$in the $\mathrm{x}-\mathrm{y}$ GSE plane, (b) $\mathrm{O}^{+}$density, (c) magnitude of the velocity in the z-y plane, (d) current calculated from $\mathrm{j}=$ nev, and assuming the width of the current sheet is $2000 \mathrm{~km}$, (e) total current, determined from knowing the total pressure and thus the lobe field, and (f) fraction of the total current carried by $\mathrm{O}^{+}$. 


\subsection{Observations on 17 August 2001}

[12] Another example when the Cluster satellites were in the plasma sheet during a geomagnetic storm is 17 August 2001. For this event, the Cluster coverage includes the initial sudden storm commencement and the main phase development, but ends before the minimum Dst or recovery phase. Figure 6 shows an overview of the time period from 16:00 to 16:50 UT, when a substorm occurred during the storm main phase, when Dst was dropping. Figure 6 is in the same format as Figure 1. Figure 6a shows the total pressure. The main increase in pressure associated with the substorm occurred over the hour prior to 16:00 UT. The substorm onset, when the total pressure starts to decrease is at 16:24 UT. Again, the overall pressure decrease is large, about a factor of 5 in this case. Oxygen beams were present in both the lobe and plasma sheet prior to this substorm, as was shown by Sauvaud et al. [2004], so we again have an event where the plasma sheet is oxygen rich prior to substorm onset. As in the 1 October event, the spacecraft are very close to the neutral line when the substorm onset occurs. Figure $6 \mathrm{~d}$ shows the $\mathrm{H}^{+}$velocity in $\mathrm{X}$. A tailward flow is observed at 16:23, then a short period of earthward flow at 16:37, tailward again at 16:39:30, and finally earthward again at 16:43:50. The current sheet half-thickness, shown in Figure 6e, decreases to $1000 \mathrm{~km}$. After substorm onset, the $\mathrm{H}^{+}$(in black) density and pressure decrease significantly, while the $\mathrm{O}^{+}$(in blue) pressure remains high. From 16:36 to $16: 46 \mathrm{UT}^{+} \mathrm{O}^{+}$is now the dominant ion in the plasma sheet. Figures $7 \mathrm{a}$ and $7 \mathrm{~b}$ show phi distributions of the energetic $(30-40 \mathrm{keV}) \mathrm{H}^{+}$and $\mathrm{O}^{+}$ from $\mathrm{S} / \mathrm{C} 1$. There are three brief time periods when duskward anistropies are observed in $\mathrm{O}^{+}$. These are again indicated with the red lines, and a red bar on the time axis. Figures $7 \mathrm{c}$ and $7 \mathrm{~d}$ show the phi distributions for the energetic $\mathrm{O}^{+}$from $\mathrm{S} / \mathrm{C} 3$ and 4 . The other spacecraft observe the duskward streaming distributions at the same times. Figures $7 \mathrm{e}$ and $7 \mathrm{f}$ give $\mathrm{B}_{\mathrm{x}}$ and $\mathrm{B}_{\mathrm{z}}$ in GSE for the three spacecraft. From $B_{x}$ we can see that during the first time period of duskward flow, $\mathrm{S} / \mathrm{C} 3$ (red) was close to the southern lobe, $\mathrm{S} / \mathrm{C}$ 1(black) was in the southern plasma sheet, and S/C 4 (blue) crossed the neutral sheet from south to north, and then back. In the second time period, S/C 3 is in the southern plasma sheet, while $\mathrm{S} / \mathrm{C} 1$ and 3 are both in the northern plasma sheet, and in the third time period, $\mathrm{S} / \mathrm{C}$ 3 is south, S/C 4 is north, and S/C 1 is very close to the neutral sheet. The fact that the duskward streaming plasma is observed on all spacecraft during these times shows that the duskward streaming distribution does extend throughout the plasma sheet. Figure 8 shows the contributions to the calculation of the current from these duskward streaming ions. Because there were, in this case, some lowerenergy $\mathrm{O}^{+}$ions which were field aligned, we have limited the energy range of the density and velocity calculations to only include the energetic ions from $17-40 \mathrm{keV}$. The calculation is done similarly for all three spacecraft. S/C 3, which remained the furthest from the central plasma sheet had a lower density, which resulted in a lower calculated current. S/C 4, which crossed the neutral sheet during the first time period had the highest current for this time period. However, in the last time period, when $\mathrm{S} / \mathrm{C} 1$ was closest to the neutral sheet, it had the smallest calculated current. We find that the contribution to the current from these ions is as high as $10 \%$, but is normally about $5 \%$.

\subsection{Observations on 11 October 2001}

[13] The final example is from a substorm which occurred during a non-storm-time period. The Dst was steady at about $-30 \mathrm{nT}$ during this time. Figure 9 gives the overview, in the same format as Figures 1 and 6. The general profile of the substorm is very similar to the previous substorms observed. Figure 9a shows the total pressure. The pressure increase and decrease is similar to the other substorms, although the maximum pressure is not as high, and the decrease is not as large. Figure $9 \mathrm{~d}$ shows the $\mathrm{H}^{+}$velocity. The spacecraft observes tailward flow, starting at 3:25 UT. This switches to earthward flow at about 3:34 UT. The spacecraft must be located close to the neutral line. Figure 9e shows the current sheet thickness. There is an extended time from $3: 35$ to $3: 42$ UT when the current sheet half-thickness again becomes about $1000 \mathrm{~km}$ thick during the earthward flow time period. Figures $9 \mathrm{~g}$ and $9 \mathrm{i}$ give the $\mathrm{O}^{+} / \mathrm{H}^{+}$pressure and density ratios. There is an increase in the ratio from $3: 33$ to $3: 37$, but the $\mathrm{O}^{+}$never exceeds the $\mathrm{H}^{+}$in either pressure or density. Figure 10 is in the same format as Figure 7. Figures $10 \mathrm{a}$ and $10 \mathrm{~b}$ show the angular distributions of the energetic $\mathrm{H}^{+}$and $\mathrm{O}^{+}$on $\mathrm{S} / \mathrm{C} 1$. From $3: 31$ to 3:42 UT, duskward streaming $\mathrm{O}^{+}$ions are observed. At the same time, the $\mathrm{H}^{+}$ions are streaming earthward. Figures $10 \mathrm{c}$ and $10 \mathrm{~d}$ show the $\mathrm{O}^{+}$phi distributions for $\mathrm{S} / \mathrm{C} 3$ and $\mathrm{S} / \mathrm{C} 4$. All spacecraft show the same distributions. Figure $10 \mathrm{~d}$ shows Bx for the three spacecraft. The spacecraft locations during this time cover the northern and southern plasma sheet, and cross the neutral sheet several times. Thus this distribution is observed throughout the thin plasma sheet. Figure 11, in the same format as Figures 5 and 8, gives the current contribution of the duskward streaming $\mathrm{O}^{+}$for the three spacecraft, using moments integrated over the full energy range. In this case the contribution calculated using the different spacecraft is remarkably similar, again emphasizing that the distribution is observed throughout the plasma sheet. The current calculated at the three spacecraft show that the $\mathrm{O}^{+}$contributes only about $3 \%$ of the total current.

\section{Discussion and Conclusions}

[14] We have examined three substorms which resulted in thin current sheets in the Cluster data set to look for evidence of nonadiabatic motion in the ions, and to determine how much these ions contribute to the cross-tail current. Two examples were from storm-time events, and one was a non-storm-time event. All events were observed after substorm onset, and when the spacecraft was on the earthward side of the neutral line. The main difference between storm-time and non-storm-time events was the amount of $\mathrm{O}^{+}$in the plasma sheet. In the storm-time events, $\mathrm{O}^{+}$was the dominant ion both in terms of density and pressure when it was observed to stream from dawn to dusk. In all the events, the signatures of nonadiabatic ion motion were observed when the current sheet was sufficiently thin. The signature of the ion motion that we observed was a partial ring distribution in the $\mathrm{v}_{\mathrm{y}}-\mathrm{v}_{\mathrm{z}}$ plane. Simulations of distribution functions expected in thin current sheets [e.g., 


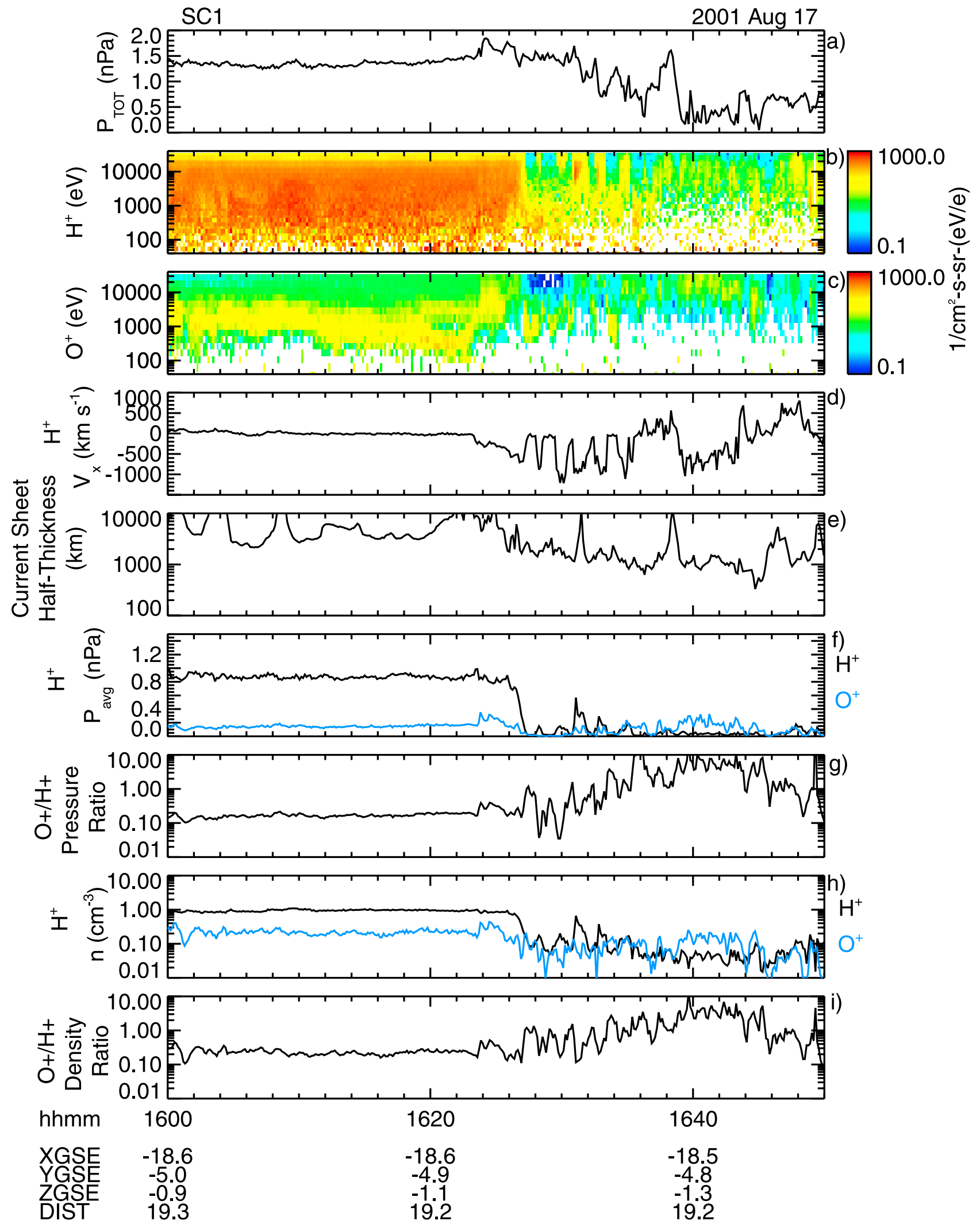

Figure 6. (a-i) Data from 17 August 2001 from 16:00 to 16:50 in the same format as Figure 1.

Burkhart et al., 1992; Sitnov et al., 2004; Lottermoser et al., 1998] have predicted a partial ring distribution. However, the partial ring distribution they predict is in the $\mathrm{v}_{\mathrm{y}}-\mathrm{v}_{\mathrm{x}}$ plane. This implies the ions are oscillating in $\mathrm{x}$, not in $\mathrm{z}$, while they stream from dawn to dusk. The reason for the difference is twofold. First, the ring distribution shown in the simulations is in the $\mathrm{z}=0$ plane, where the magnetic field is nominally in the $\mathrm{z}$ direction. Thus the gyromotion of the ions is in the 

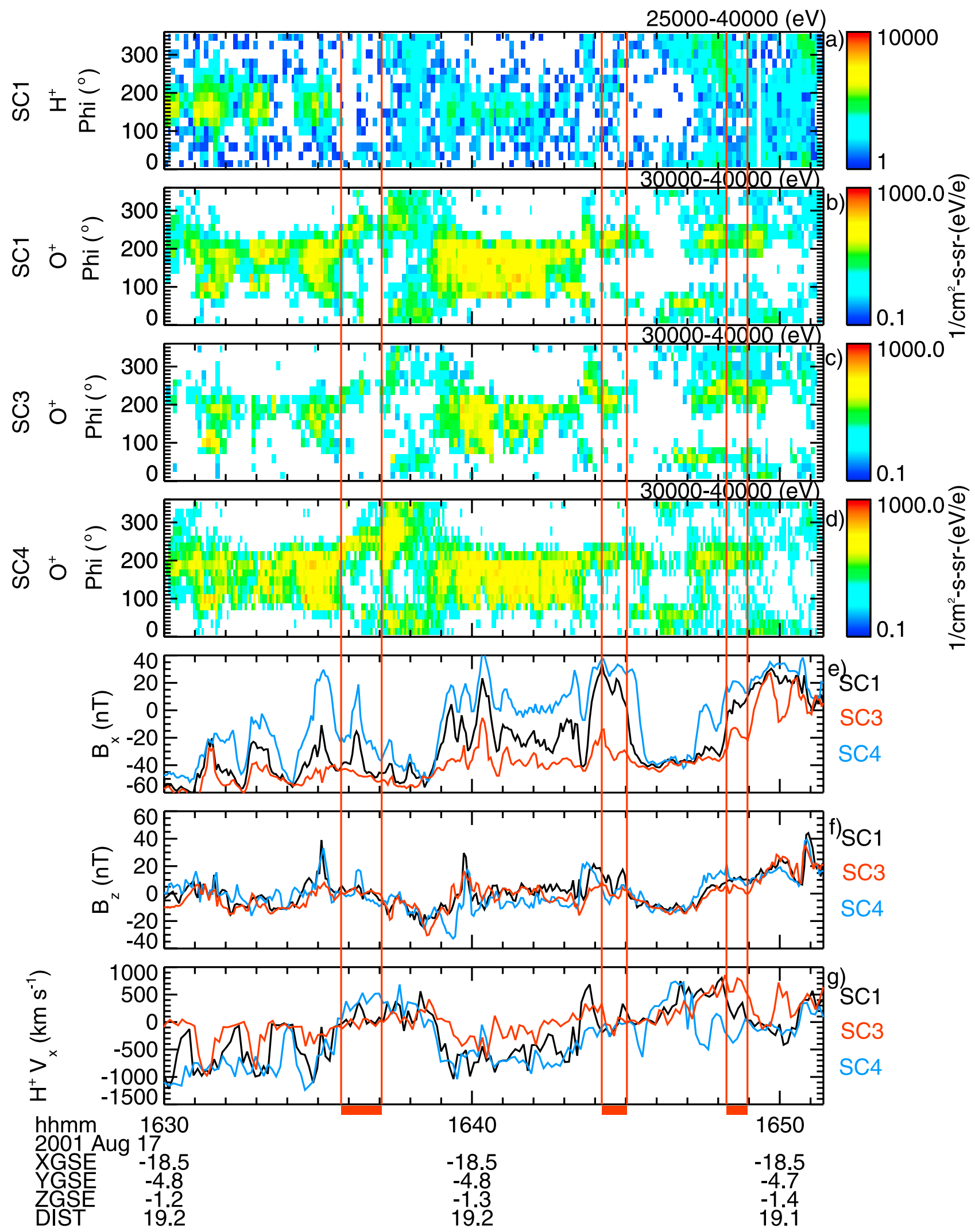

Figure 7. (a) $\mathrm{S} / \mathrm{C} 1 \mathrm{H}^{+}$angular distribution in approximately the $\mathrm{x}$-y GSE plane, for $25-40 \mathrm{keV}$ ions. The duskward direction corresponds to 250 degrees. (b-d) S/C 1, S/C 3, and $\mathrm{S} / \mathrm{C}_{4} \mathrm{O}^{+}$angular distribution approximately the $x-y$ GSE plane, for $30-40 \mathrm{keV}$ ions. (e and f) $B_{x}$ and $B_{z}$ in GSE coordinates for S/C 1 (black), S/C 3 (red), and S/C 4 (blue). (g) $\mathrm{H}^{+} \mathrm{V}_{\mathrm{x}}$ in GSE coordinates for S/C 1 (black), S/C 3 (red), and S/C 4 (blue). 

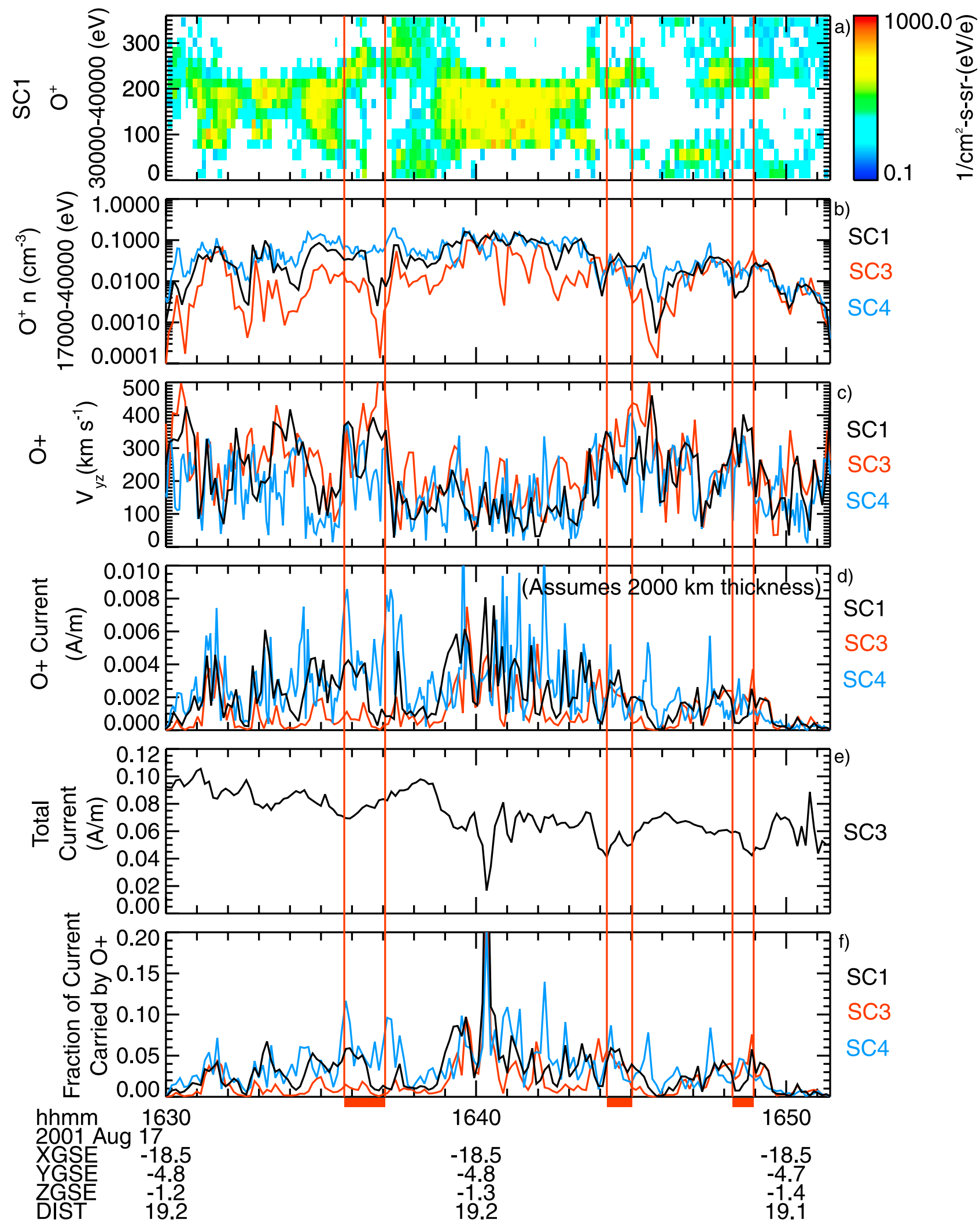

Figure 8. (a-f) Same format as Figure 5 for the time period 17 August, 16:00-16:53, showing the data from $\mathrm{S} / \mathrm{C} 1$ (black), S/C 3 (red), and S/C 4 (blue). 

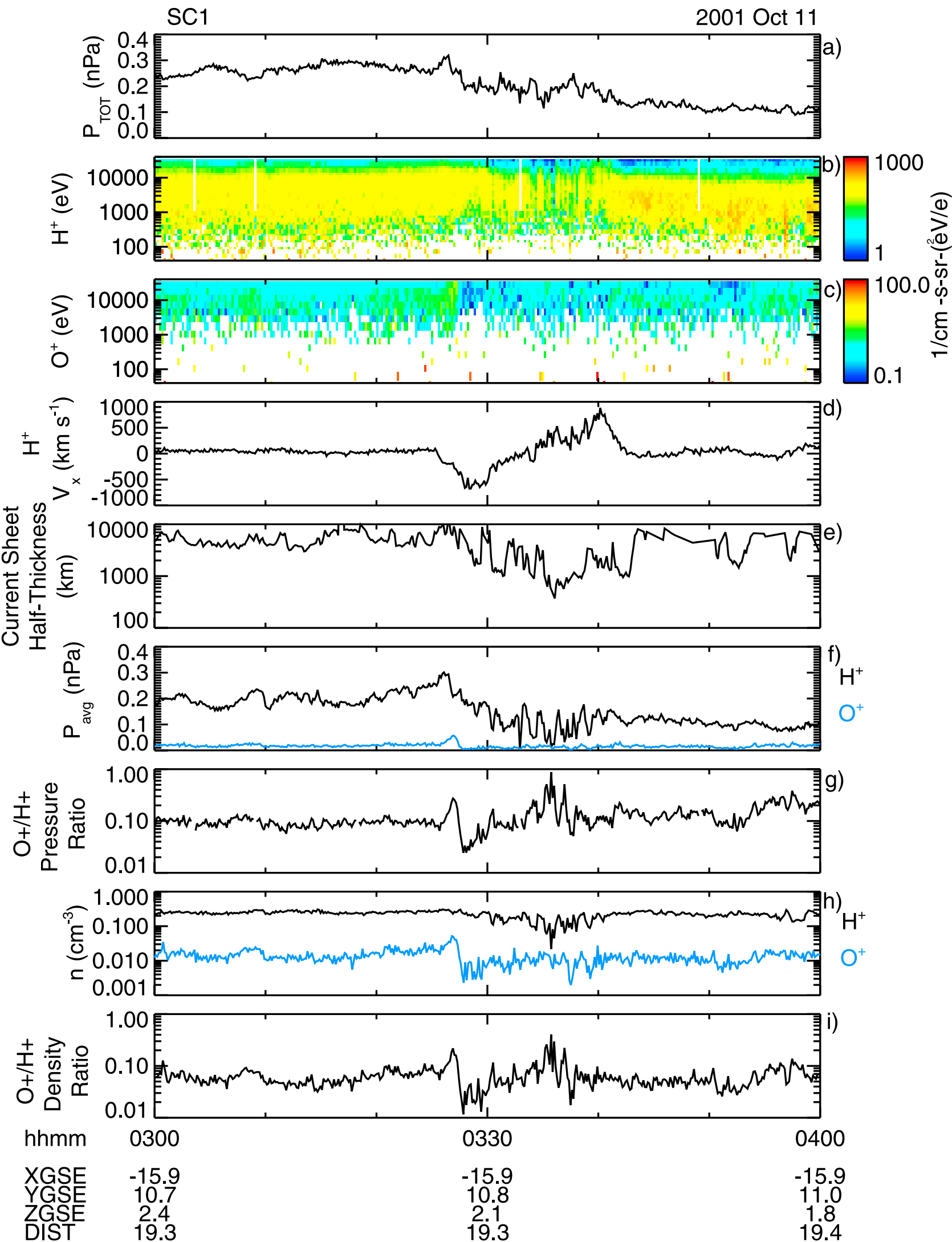

Figure 9. $(\mathrm{a}-\mathrm{i})$ Data from 11 October 2001 from 03:00 to 04:00 in the same format as Figure 1. 

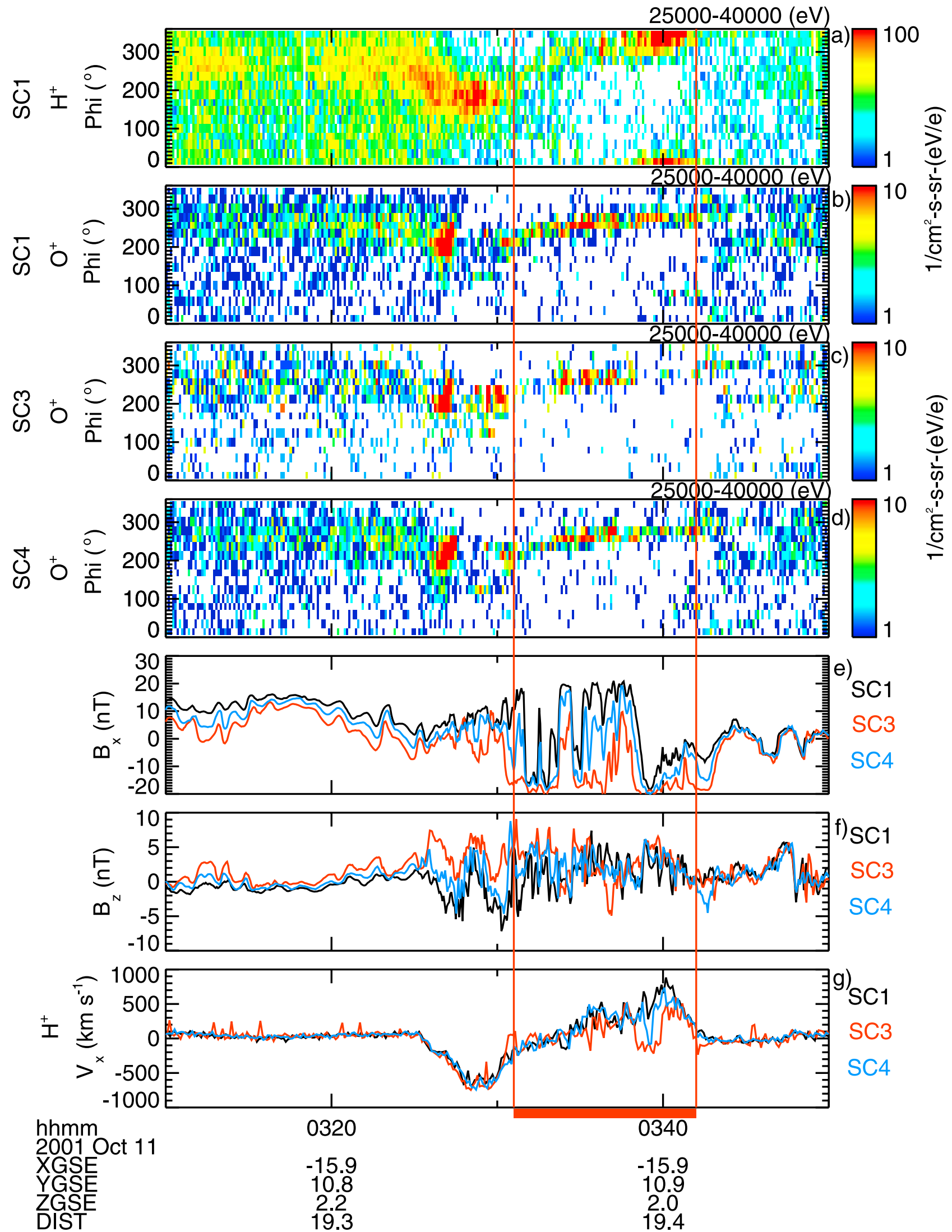

Figure 10. $(a-g)$ Angular distributions, $\mathrm{B}_{\mathrm{x}}$ and $\mathrm{B}_{\mathrm{z}}$, and $\mathrm{H}^{+} \mathrm{V}_{\mathrm{z}}$, in the same format as Figure 7 for 11 October 3:10-3:50. 


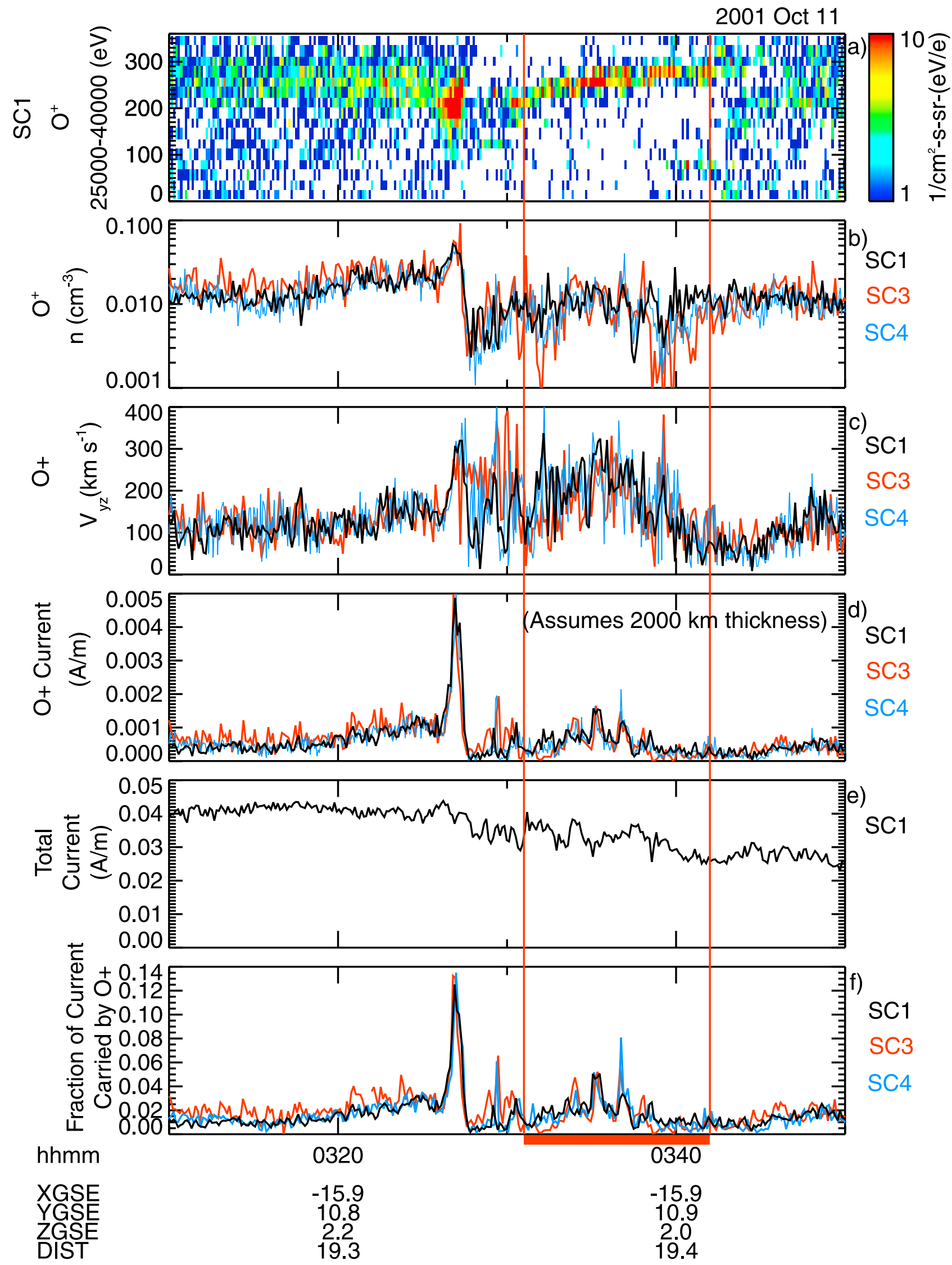

Figure 11. (a-f) Same format as Figure 5 for the time period 11 October, 3:10-3:50, showing the data from $\mathrm{S} / \mathrm{C} 1$ (black), S/C 3 (red), and S/C 4 (blue). 
$x-y$ plane. In contrast, the Cluster spacecraft are essentially never located long enough at $\mathrm{z}=0$ to measure a distribution. The measured distributions are normally from a location where the field is predominantly in the $\mathrm{x}$ direction, so the gyromotion is in the $y-z$ plane. The second difference is that in the simulations, the velocity distributions outside $\mathrm{z}=0$ are predominantly field aligned, streaming in the $\mathrm{x}$ direction. In the cases that we are observing, the ions outside $\mathrm{z}=0$ are predominantly at $90^{\circ}$ pitch angle. Thus they have a substantial velocity in $\mathrm{z}$ when they approach the neutral sheet which leads to the oscillating motion in $\mathrm{z}$ sketched in Figure 2, and which is reflected in the distributions.

[15] The magnitude of the current carried by these ions was at most $10 \%$, and usually less. This was determined both by comparing the measured current to the overall current expected for the given lobe magnetic field, and by comparing it to the locally measured current density determined from the curlometer technique by Runov et al. [2003]. This indicates that even when the pressure is dominated by $\mathrm{O}^{+}$, the main current carriers are either the electrons, as found by Asano et al. [2003], or are the protons, although the protons are not the dominant ion. The model of Sitnov et al. [2003] showed that the contribution of ions to the current sheet depended strongly on the ion anisotropy outside the inner current sheet. In particular, if the distribution were a pancake distribution, the electrons would dominate the current in the center of the current sheet. This may be the case during our time periods. However, the model of Sitnov et al. [2003] also predicted that the maximum current density was still carried by the ions, but outside the inner current sheet, which we did not observe. Alternatively, the dominant electron current may be due to negative charging of the central plasma sheet, as in the model of Pritchett and Coroniti [1995]. This model would predict an electric field directed toward the neutral sheet, and equivalently a convective flow in -vy outside the central current sheet. Finally, the electron dominance may result from our location close the reconnection site in these three cases. Lottermoser et al. [1998] used hybrid simulations of reconnection to show that the current within about 40 ion inertial lengths of the neutral line was dominated by electrons, but the ions became dominant further away. Additional work will be needed to determine which models best fit the observations.

[16] Acknowledgments. We are grateful to the many engineers and scientists from UNH, MPE, CESR, MPAe, IFSI, IRF, UCB, and UW who made the development of the CIS instrument possible. We thank M. Sitnov for helpful discussions. Development of the CIS instrument in the U.S. and this work were supported by NASA contract NAS5-30613 and grants NAG5-10131 and NAG5-12762.

[17] Lou-Chuang Lee thanks Joachim Birn and Donald Mitchell for their assistance in evaluating this paper.

\section{References}

Asano, Y., T. Mukai, M. Hoshino, Y. Saito, H. Hayakawa, and T. Nagai (2003), Evolution of the thin current sheet in a substorm observed by Geotail, J. Geophys. Res., 108(A5), 1189, doi:10.1029/2002JA009785.
Burkhart, G. R., J. F. Drake, P. B. Dusenbery, and T. W. Speiser (1992), A particle model for magnetotail neutral sheet equilibria, J. Geophys. Res., 97, 13,799.

Eastwood, J. W. (1972), Consistency of fields and particle motion in the "Speiser" model of the current sheet, Planet. Space Sci., 20, 1555.

Eastwood, J. W. (1974), The warm current sheet model, and its implications on the temporal behaviour of the geomagnetic tail, Planet. Space Sci., 22, 1641.

Hesse, M., and D. Winske (1994), Hybrid simulations of collisionless reconnection in current sheets, J. Geophys. Res., 99, 11,177.

Hesse, M., D. Winske, M. Kuznetsova, J. Birn, and K. Schindler (1996), Hybrid modeling of the formation of thin current sheets in magnetotail configurations, J. Geomagn. Geoelectr., 48, 749.

Kropotkin, A. P., H. V. Malova, and M. I. Sitnov (1997), Self-consistent structure of a thin anisotropic current sheet, J. Geophys. Res., 102, 22,099 .

Larson, D. J., and R. L. Kaufmann (1996), Structure of the magnetotail current sheet, J. Geophys. Res., 101, 21,447.

Lottermoser, R.-F., M. Scholer, and A. P. Mattheus (1998), Ion kinetic effects in magnetic reconnection: Hybrid simulations, J. Geophys. Res., $103,4547$.

Mitchell, D. G., G. J. Williams, C. Y. Huang, L. A. Frank, and C. T. Russell (1990), Current carriers in the near-Earth cross-tail current sheet during substorm growth phase, Geophys. Res. Lett., 17, 583.

Pritchett, P. L., and F. V. Coroniti (1995), Formation of thin current sheets during plasma sheet convection, J. Geophys. Res., 100, 23,551.

Reme, H., et al. (2001), First multispacecraft ion measurements in and near the Earth's magnetosphere with the identical CLUSTER Ion Spectrometry (CIS) experiment, Ann. Geophys., 19, 1303.

Runov, A., et al. (2003), Current sheet structure near magnetic X-line observed by Cluster, Geophys. Res. Lett., 30(11), 1579, doi:10.1029/ 2002GL016730.

Sauvaud, J.-A., et al. (2004), Case studies of the dynamics of ionospheric ions in the Earth's magnetotail, J. Geophys. Res., 109, A01212, doi:10.1029/2003JA009996.

Schindler, K., and J. Birn (2002), Models of two-dimensional embedded thin current sheets from Vlasov theory, J. Geophys. Res., 107(A8), 1193, doi:10.1029/2001JA000304.

Sitnov, M. I., L. M. Zelenyi, H. V. Malova, and A. S. Sharma (2000), Thin current sheet embedded within a thicker plasma sheet: Self-consistent kinetic theory, J. Geophys. Res., 105, 13,029.

Sitnov, M. I., P. N. Guzdar, and M. Swisdak (2003), A model of the bifurcated current sheet, Geophys. Res. Lett., 30(13), 1712, doi:10.1029/2003GL017218.

Sitnov, M. I., A. T. Y. Liu, P. N. Guzdar, and P. H. Yoon (2004), Currentdriven instabilities in forced current sheets, J. Geophys. Res., 109, A03205, doi:10.1029/2003JA010123.

Speiser, T. W. (1965), Particle trajectories in model current sheets: 1. Analytical solutions, J. Geophys. Res., 70, 4219.

Wygant, J. R., et al. (2005), Cluster observations of an intense normal component of the electric field at a thin reconnecting current sheet in the tail and its role in the shock-like acceleration of the ion fluid into the separatrix region, J. Geophys. Res., doi:10.1029/2004JA010708, in press.

A. Balogh, Space and Atmospheric Physics, Imperial College, London SW7 2BZ, UK.

L. M. Kistler, E. Möbius, and C. Mouikis, Space Science Center, 410 Morse Hall, University of New Hampshire, Durham, NH 03824, USA. (lynn.kistler@unh.edu)

B. Klecker, Max-Planck-Institute für Extraterrestriche Physik, KarlSchwarzschild Str. 1, Postfach 1312, Garching D-85741, Germany.

A. Korth, Max-Planck-Institute für Aeronomie, Max-Planck Str. 2, Postfach 20, Katlenburg-Lindau D-37191, Germany.

R. Lundin, Swedish Institute for Space, P.O. Box 812, Kiruna SE-98128, Sweden.

M. F. Marcucci, Istituto di Fisica dello Spazio Interplanetario, Via del Fosso del Cavaliere, 100, Rome I-00133, Italy.

G. K. Parks, Space Sciences Laboratory, University of California, Berkeley, CA 94720, USA.

H. Réme and J. A. Sauvaud, Centre d'Etude Spatiale des Rayonnements, 9 Avenue du Colonel Roche, BP 4346, Toulouse F-31028, France. 